\title{
El irredentismo como instrumento de la geopolítica y estrategia rusa*
}

\author{
Camilo Andrés Devia Garzón** \\ Juan Carlos García Perilla*** \\ Ángela María Herrera Castillo****
}

\section{RESUMEN}

El irredentismo es una campaña política para unir un grupo minoritario que pertenece a un país, con un Estado vecino que esgrime el argumento de que este grupo se identifica con su identidad nacional, su cultura, su historia, su etnia o su religión. Este artículo expondrá, desde la geopolítica neoclásica y crítica, cómo este fenómeno es utilizado por el Gobierno de Vladimir Putin dentro de su estrategia para detener el avance de la OTAN en sus zonas de influencia, anexando territorios que antes pertenecían a Estados como Ucrania o Georgia donde habitan ciudadanos rusos.

Palabras clave: irredentismo, nacionalismo, geopolítica, Rusia.

Este artículo es producto de la investigación titulada "Irredentismo: la vigencia de la ideología nacionalista en el caso ucraniano", desarrollada en el año 2016 y registrada con el código INV eEs 2087 de la Universidad Militar Nueva Granada (Colombia)

** Magíster en Asuntos Internacionales, Universidad Externado de Colombia. Docente investigador, Programa de Relaciones Internacionales y Estudios Políticos, Universidad Militar Nueva Granada, Bogotá (Colombia). [camilo. devia@unimilitar.edu.co].

http://orcid.org/0000-0002-6264-4958

*** Magíster en Seguridad y Defensa Nacionales de la Escuela Superior de Guerra. Docente investigador del Programa de Relaciones Internacionales y Estudios Políticos, Universidad Militar Nueva Granada, Bogotá (Colombia). [juan. garcia@unimilitar.edu.co].

http://orcid.org/0000-0002-9620-4635

**** Especialista en Ambiente y Desarrollo Local, Universidad Distrital "Francisco José de Caldas". Estudiante de la Maestría en Estudios Sociales interdisciplinares, Universidad Distrital “Francisco José de Caldas", Bogotá (Colombia). [anmaheca@gmail.com].

Recibido: 3 de marzo de 2017 / Modificado: 23 de marzo de 2017 / Aceptado: 27 de marzo de 2017

Para citar este artículo:

Devia Garzón, C. A., García Perilla, J. C. y Herrera Castillo, A. M. (2017). El irredentismo como instrumento de la geopolítica y estrategia rusa. OASIs, 26, 81-105.

DOI: https://doi.org/10.18601/16577558.n26.06 


\section{Irredentism as an instrument of the russian geopolitics and strategy}

\section{ABSTRACT}

Irredentism is a political campaign aiming to unite a minority group belonging to a country, with a neighboring state, by wielding the argument that this group identifies with their national identity, their culture, their history, their ethnicity or their religion. This article will expose from neo-classical and critical geopolitics, how this phenomenon is used by the Government of Vladimir Putin in its strategy to stop the advance of NATO in their zones of influence, annexing territories that previously belonged to States such as Ukraine or Georgia where Russian citizens live.

Key words: Irredentism, nationalism, geopolitics, Russia.

\section{QUÉ ES EL IRREDENTISMO}

El irredentismo proviene de la palabra italiana irredenta, que significa sin redimir. Surge como movimiento político en 1866 para anexar las regiones Trentino, Friuli y Venecia Giulia, que se encontraban bajo la dominación austriaca, a Italia (Domínguez, 2013). Desde entonces, el irredentismo ha llegado a abarcar cualquier esfuerzo político para unir en los aspectos étnicos, históricos y geográficos segmentos relacionados de una población en países adyacentes dentro de un marco político común, en este caso Rusia con los eslavos o ciudadanos rusos que habitan las provincias orientales de Ucrania y el sur de Georgia.

Estos procesos políticos, ya sea a través de guerras o impugnación de tratados, conllevan reclamaciones de algún Estado, grupo o movimiento político que buscan como resultado una reconfiguración territorial (Centro de Estudios Estratégicos de la ANEPE, 2014).

Históricamente, el irredentismo no puede separarse de la ideología nacionalista en su vertiente conservadora y negativa, la cual se caracteriza por las posturas diferenciadoras entre comunidades por su historia, valores, lengua, tradiciones, territorio y cultura, tendencia que surge en la Alemania del siglo XIX con Johann Herder y Johann Fichte (Gómez, 2008). Por tanto, pueden surgir fenómenos irredentistas en comunidades que viven en países diferentes (por tratados o guerras) al que por naturaleza deberían pertenecer.

En Ucrania es notoria esta diferenciación entre dos de las comunidades que residen en este país, una europea y otra ruso-eslava. Parte de esta última población busca anexarse a Rusia por vía democrática o armada dándose el fenómeno descrito. En el caso de Georgia, en 1992 y 2006, los ciudadanos de Osetia del Sur votaron masivamente para ser incorporados a Rusia y separarse definitivamente de Georgia, ya que la mayoría de su población tiene nacionalidad rusa.

\section{GEOPOLÍTICA Y ESTRATEGIA DE RUSIA}

Las teorías geopolíticas siempre han reivindicado la capacidad de decirnos cómo va a ser el mundo -qué y dónde estarán las futuras amenazas-y, por tanto, ofrecer prescripciones o implicaciones políticas (Ó Tuathail, 1996). 
Desde los años noventa se evidencian dos tendencias principales en el ámbito de la geopolítica: la neoclásica y la crítica. Se puede analizar la estrategia rusa desde una perspectiva más amplia al utilizar estas dos corrientes, ya que son complementarias al abordar desde sus postulados elementos distintos que permiten un análisis más amplio del fenómeno.

Con la geopolítica neoclásica se estudiará primordialmente desde el Estado, el espacio, la geografía y el territorio, la Estrategia de Seguridad Nacional y la Doctrina Militar del Gobierno ruso con las cuales pretende recuperar su influencia en los países de la antigua Unión Soviética. A partir de la perspectiva crítica se examinará, desde la geografía humana, el ámbito ideológico y cultural de los discursos de contenido nacionalista e irredentista de los líderes políticos, especialmente Vladimir Putin, y la interpretación de los documentos oficiales rusos.

\section{GEOPOLÍTICA NEOCLÁSICA}

La corriente neoclásica retoma el Estado y su interacción con entornos geográficos como núcleo epistemológico del análisis ya que la relevancia del territorio, las fronteras internacionales, los recursos naturales, el poder internacional y la influencia geopolítica permanecen vigentes (Cardona, 2012).

Esta tendencia es entendida como "la competencia entre las grandes potencias y los aspirantes a serlo por el control de territorio, recursos e importantes posiciones geográficas" (Klare, 2003, p. 51). En este contexto, los Estados siguen siendo la unidad fundamental de análisis, manteniéndose los conceptos de poder nacional e intereses nacionales como primordiales. Para la geopolítica neoclásica, los Estados se encuentran en un constante conflicto por los espacios entendidos, no como referentes discursivos utilizados por los actores políticos para legitimar sus deseos de poder, sino como objetos físicos y reales, no solo en términos de territorios, sino también de otros espacios (Murphy, 2004).

La geopolítica neoclásica recibe su nombre del uso de postulados de autores clásicos de la geopolítica como Hauschofer, Spykman y Mackinder para interpretar y guiar las actuaciones de los Estados en el mundo contemporáneo. Por esta razón, esta geopolítica presenta un componente orientado a la acción que se traduce en la vigencia del concepto de Heartland, aún ubicado en Eurasia. Para la geopolítica neoclásica es fundamental controlar Asia Central y evitar el surgimiento de un hegemón en la región debido a su posición geoestratégica y sus abundantes recursos energéticos (Fettweis, 2000).

En esta vertiente "la materialidad del mundo se asume como objetiva y, como tal, se encuentra más allá de cualquier tipo de intencionalidad humana, incluyendo aquella que surge de la negociación del poder político" (Murphy, 2004, p. 621). Esta versión de la disciplina sugiere que el espacio es una variable independiente y objetiva que determina el comportamiento político de las sociedades dando cuenta de dinámicas políticas complejas mediante el análisis del espacio geográfico, por tanto, el análisis político está atado al territorio como condición de existencia, supervivencia y poder de los Estados.

En la corriente neoclásica cada Estado presenta unas características geopolíticas es- 
pecíficas que lo diferencian de los otros, las cuales se clasifican en fortalezas y debilidades internas, así como oportunidades y amenazas que surgen de su relación con el entorno. La política de seguridad se respalda por las fortalezas internas y se orienta a maximizar las oportunidades y minimizar las amenazas (Ruiz González, 2016).

A partir de lo anterior, Rusia tiene como objetivos recuperar su imagen imperial y convertirse nuevamente en una potencia global con presencia internacional, haciendo una defensa activa de sus áreas de influencia (espacios donde hay, en varios casos, presencia de minorías rusas) con la creación de un cinturón de seguridad o escudo geográfico entre Rusia y Europa (Ferrero Turrión, 2016). Estos objetivos surgen del progresivo acercamiento de la Organización del Tratado del Atlántico Norte (OTAN) a sus fronteras, a fin de ocupar espacios que hacían parte de la antigua Unión Soviética.

Para lograr sus objetivos está utilizando el poder duro a través de sus políticas de seguridad y defensa (Doctrina Militar y Estrategia de Seguridad Nacional), y el poder blando utilizando las vías diplomática, económica, social y cultural orientadas hacia la población rusa que reside fuera de sus fronteras, a fin de generar simpatías prorrusas en la periferia de la Unión Europea, lo que ha hecho reaparecer el irredentismo ruso (Ferrero Turrión, 2016). En los casos de Crimea, Abjasia y Osetia del Sur que se desarrollarán más adelante, se refleja la utilización de estos dos poderes por parte de Rusia.

Las áreas de influencia rusa o, como ellos mismos las denominan, áreas de especial inte- rés, hacen referencia a los territorios denominados espacios postsoviéticos o extranjero próximo (se encuentra con el mismo sentido del término exterior próximo), al que pertenecen países que conformaron el antiguo bloque socialista y tienen un gran valor geopolítico para Rusia. Entre ellos están Estonia, Letonia, Lituania, Polonia, Bielorrusia, Moldavia, Ucrania y Georgia, principalmente. Para la dirigencia rusa estos países no deberían actuar contra los intereses estratégicos rusos (figura 1).

A lo largo de los siglos, estos espacios postsoviéticos han sido zonas de disputa, de frontera, de tránsito y comercio, de asentamiento y migraciones forzadas, límites de imperios, y han constituido una zona-colchón y campo de batalla entre Rusia, con sus distintas denominaciones y realidades a lo largo de la historia, y muchas naciones no solo del continente europeo y asiático, sino de todo el planeta, ya que constituyen unidades prioritarias en la influencia y dominación a escala global (Herráez, 2015).

Con respecto al uso y la combinación de instrumentos de poder blando con los de poder duro en las áreas de especial interés se destacan en el primer poder, desde la ideología nacionalista, la denominada "pasaportización", los medios de comunicación como RT y las redes sociales, la religión ortodoxa, el idioma ruso y los eventos deportivos (González, 2010). En lo referente al duro, Rusia ha hecho uso de sus fuerzas armadas fuera de sus fronteras anexando territorios (Crimea) o generando la conformación de nuevos Estados afines a su influencia e intereses (Osetia del Sur), ha 
enviado comandos encubiertos (Donetsk y Lugansk), además del fortalecimiento y mantenimiento de sus contingentes militares en el exterior o en sus enclaves (Kaliningrado) (fi- gura 2). También ha utilizado este poder desde lo económico realizando bloqueos comerciales, subiendo los precios del gas o congelando su suministro (Ucrania).

Figura 1

Ubicación territorios en disputa en antiguos países el bloque soviético

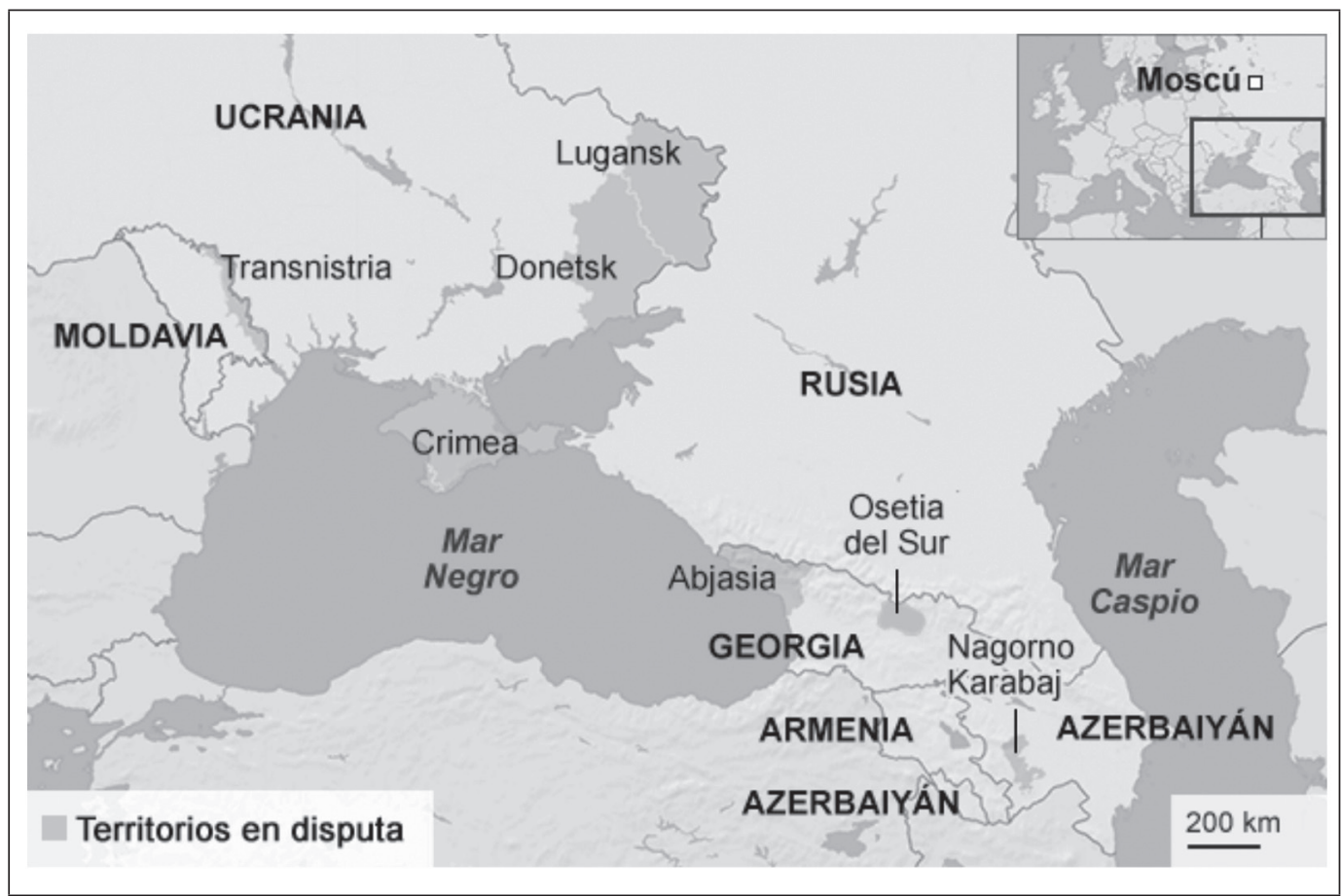

Fuente: BBC (2014b). 
Figura 2

Ubicación del enclave de Kaliningrado

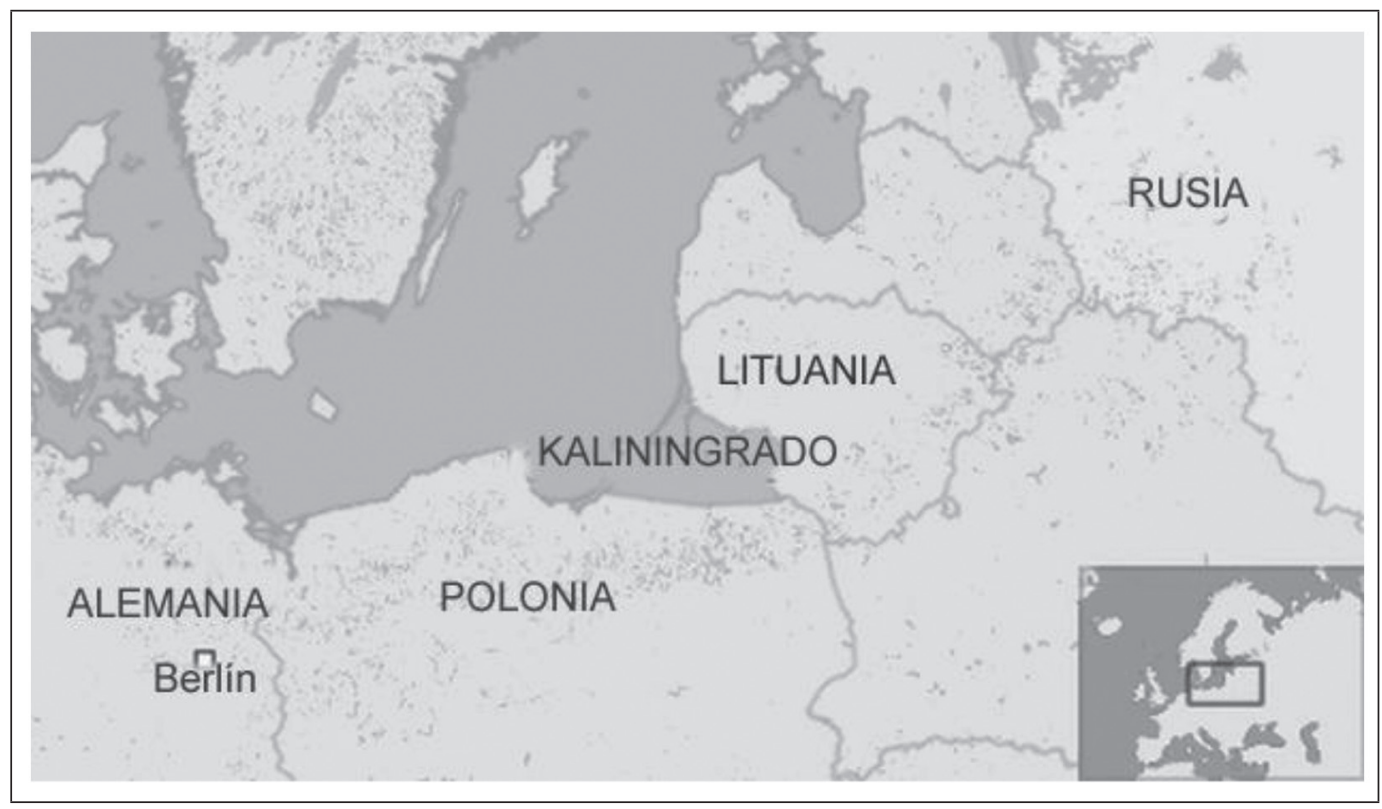

Fuente: BBC (2016)

Los usos de estos poderes se potencian o limitan con base en las fortalezas y debilidades de Rusia. Entre las primeras se encuentran el liderazgo de Vladimir Putin, el poderío militar que incluye su arsenal nuclear, ser el país más grande de la tierra, el noveno en población absoluta, sus recursos naturales (petróleo y gas) y la estructura administrativa/territorial descentralizada y relativamente eficaz. Entre sus debilidades se destaca el carecer de fronteras física y claramente delimitadas, por ello mantiene abiertos diversos litigios con sus vecinos; tener la densidad de población más baja del planeta con un crecimiento demográfico estancado; su economía golpeada por las sanciones de Estados Unidos y Europa; la excesiva dependencia de la exportación de materias primas; su gran diversidad étnica y religiosa que es fuente de conflictos, y su infraestructura que no ha sido apropiadamente renovada desde la época soviética (González, 2010).

Los elementos expuestos son el soporte de la Doctrina Militar Rusa y la Estrategia de Seguridad Nacional, establecidas por Vladimir Putin desde que accedió al poder. La Doctrina protege los intereses nacionales rusos, resalta el impacto político que tienen sobre la seguridad nacional rusa el auge de los nacionalismos, los centros de poder regionales, los movimientos extremistas (étnicos y religiosos) y de separatismo, por lo que se invita a reforzar y proteger la unidad rusa (Pérez, 2015). 
En la Doctrina Militar de 2010 se define el sistema de valores y principios que direccionan al Estado a la hora de determinar cuándo se debe recurrir a acciones militares. En esta versión se precisan como peligros para la Federación Rusa: la expansión de la OTAN hacia el oriente de Europa y su acercamiento progresivo hacia las fronteras rusas, la desestabilización de Estados y regiones para ganar poder estratégico, la colaboración militar de la OTAN con Estados vecinos, el desarrollo del escudo estadounidense de misiles balísticos desplegado en Europa, y las reivindicaciones territoriales que puedan contradecir los intereses rusos y, en general, la estabilidad regional.

Estos peligros refuerzan la idea rusa de desconfianza hacia el potencial invasor enfatizando la diferencia entre Rusia y Occidente, y justifica la dominación sobre lo que considera su indiscutible espacio vital anhelando fortalecer la influencia en la región, retomando la idea de unificación de los pueblos eslavos bajo su liderazgo.

Esta postura de desconfianza rusa tiene también una explicación histórica y ha sido su geografía única, factor que ha configurado su papel en el mundo al no tener fronteras naturales, excepto los océanos Pacífico y Ártico, por lo que se siente vulnerable. Por tal razón exhibe una agresividad defensiva y una postura de seguridad que se basa en el movimiento hacia afuera, en nombre del ataque previo externo, donde los países más pequeños en sus fronteras son vistos más como posibles aliados de los enemigos que como potenciales amigos (Kotkin, 2016).

Putin, con esta Doctrina, pretende que Rusia sea de nuevo considerada un centro global de poder político y militar pese a las dificultades económicas que actualmente tiene el país. En consecuencia, propende por ser tenido en cuenta para las negociaciones en temas de importancia para Rusia como el control de armas nucleares y la eliminación de sanciones; a su vez, anhela desvincular la política doméstica de las relaciones con el Este toda vez que hay una separación entre el discurso y la política real, motivos por los cuales considera deshonestos los principios declarados por Occidente (Arbatov, 2016).

Esta Doctrina se actualizó en diciembre del 2014, retomando lo planteado en la del 2010 y adaptándose a los cambios en el ámbito de la seguridad en particular, las revoluciones de colores y la guerra civil en Ucrania. Reafirma que la OTAN es una de las principales amenazas para Rusia por la aproximación de la infraestructura militar de esta organización a sus fronteras mediante la estrategia de una mayor expansión. Lo novedoso es que el Gobierno ruso se reserva el derecho de utilizar armas nucleares en respuesta a ataques con armas de destrucción masiva en contra suya o sus aliados, así como en el caso de una agresión con armas convencionales que suponga una amenaza para la existencia del Estado (Sinovets y Renz, 2015).

Por su parte, la Estrategia de Seguridad Nacional, la cual fue actualizada el 31 de diciembre del 2015, retoma casi los mismos elementos (las amenazas y los peligros a la seguridad nacional) expuestos en la Doctrina Militar de 2010 y 2014, donde se establecen las bases para la planificación estratégica, se definen los intereses nacionales, las prioridades, los objetivos, las tareas y las medidas en el ámbito 
de la política interna y externa, con los objetivos de reforzar la seguridad nacional del país y garantizar su desarrollo sostenible, además de señalar que para afrontar las amenazas a la seguridad nacional Rusia centrará sus esfuerzos en el fortalecimiento de la unidad interna de la sociedad rusa, la armonía interétnica, la tolerancia religiosa, la eliminación de los desequilibrios estructurales, la modernización de la economía y la mejora de la capacidad defensiva del país (Iglesias, 2016).

La última versión de esta estrategia incluye como amenazas las actividades de las asociaciones radicales y grupos que usan la ideología nacionalista y religiosa extremista, ONG extranjeras cuyas actividades se centran en la destrucción de la unidad y la integridad territorial rusa, la desestabilización de la política interna y de la situación social, la destrucción de los valores morales y religiosos rusos, y las revoluciones de colores (Iglesias, 2016) como las ocurridas en Georgia y Ucrania, fenómeno que se analizará más adelante.

Lo novedoso de esta estrategia consiste en considerar como fundamentales e imprescindibles los temas culturales y sociales en procura de revitalizar el legado histórico ruso e incitar al patriotismo (palabra que se repite en varias oportunidades en dicho documento), el espiritualismo eslavo, la protección a la unidad multinacional rusa y el respeto de las tradiciones familiares. La inclusión de estas temáticas se explica desde la geopolítica neoclásica en que el Estado aprovecha las brechas culturales y nacionales para alcanzar sus objetivos políticos para lograr su seguridad y obtener sus intereses utilizando terceros Estados en su beneficio -en este caso la Federación Rusa interviene en países vecinos, legitimando sus acciones con el discurso de la defensa y unión de los rusos étnicos y rusófonos- (Ruiz Ramas, 2016).

Desde esta perspectiva neoclásica, la intervención rusa en antiguas repúblicas soviéticas (como Georgia y Ucrania) se puede comprender como una respuesta del Gobierno de Vladimir Putin al aumento de la presencia de la Unión Europea y Estados Unidos en lo que considera sus áreas de especial interés, sumado al posible ingreso de estos a la Organización del Tratado Atlántico Norte (OTAN); por lo anterior, Rusia reivindica el discurso nacionalista irredentista como estrategia para detener el expansionismo de sus adversarios, en la que considera su zona natural de influencia, poblada en algunas regiones por comunidades prorrusas.

Desde la óptica de Robert Kagan, Rusia estaría creando una estructura de poder político sustentada en el nacionalismo de gran potencia (vertiente conservadora de la ideología nacionalista que promulga la superioridad de unas naciones sobre otras y el derecho de las primeras a expandirse y conquistar a las segundas), con el objeto de dar credibilidad a las posibilidades que existen para recuperar el papel ruso en la historia y el destino del mundo, buscando alterar el equilibrio de poder de la posguerra fría, restablecerse como una potencia dominante en Eurasia, y así consolidarse como una de las grandes potencias del mundo (Kagan, 2008).

\section{GEOPOLÍTICA CRÍTICA}

Esta vertiente surge en los años noventa consolidándose como una alternativa analítica diferente a la clásica y neoclásica, confrontándolas 
por su carácter ahistórico e ideológico, y por su pretensión de poder generar principios geopolíticos generales e inmutables. Esta corriente fue acuñada al profesor Gearóid Ó Tuathail, quien describió el término como un estudio de las políticas mundiales en la pos-Guerra Fría, época en la cual hubo una reorganización geográfica e ideológica que significó el nacimiento de diferentes fenómenos expresados en nacionalismos y conflictos étnicos-religiosos, al interior de los Estados que ocupaban el espacio postsoviético ubicado en la frontera entre Europa y Asia (Ó Tuathail, 1996).

La geopolítica crítica aún no es un campo claramente delimitado. En el sentido más amplio, se utiliza como una etiqueta para diversas perspectivas unidas por su crítica a la geopolítica clásica y los peligrosos discursos a ella asociados. En lugar de conceptualizar la política como un producto de la ideología imperial o de la lucha incesante por el poder perseguida por los Estados territoriales, el enfoque crítico de la geopolítica la ve como una práctica social, cultural, discursiva y política de construcción social de espacios e identidades (Omelicheva, 2016).

Esta vertiente de la geopolítica se parece a los enfoques constructivistas de las relaciones internacionales, ya que ambas perspectivas destacan los aspectos intangibles de la política mundial, es decir, lo mental, lo cognitivo, y las construcciones discursivas de espacios geopolíticos. Ninguno de los dos limita la seguridad del Estado a consideraciones de seguridad física, y ambos llaman la atención sobre la importancia y las prácticas de salvaguardar la seguridad y la continuidad de las estructuras de identidad de los Estados (Omelicheva, 2016).
Tres destacados autores de esta corriente son John Agnew, Simon Dalby y Géaroid Ó Tuathail. Los antecedentes directos de la geopolítica crítica norteamericana se encuentran en dos proyectos: "The World Order Models Project" y el "Global Civilization Project". Estos dos modelos implican una reorientación del conflicto internacional, una redefinición del papel del Estado y las Fuerzas Armadas, y aspectos culturales-civilizatorios en la esfera de las relaciones internacionales (Carvajal Aravena, 2007).

Los críticos reconocen que algunos factores geográficos ejercen una influencia incontrastable en el desarrollo del Estado, pero ello es de menos entidad en función de su expresión cultural. Entre estos factores la geografía humana, en su dimensión ideológica, juega un papel relevante que sobrepasa a lo geográfico como proceso estatal, de manera que centra su tarea en las interpretaciones del discurso político. Esta corriente adhiere al pensamiento de la izquierda marxista, según la cual el discurso ideológico es capaz de generar relaciones de poder que le permiten crear y consolidar estructuras sociales que posibilitan modificar las perspectivas nacional y estatal (Polgati, 2007).

La geopolítica crítica pone en duda el carácter objetivo del espacio como determinante del comportamiento político y lo interpreta más bien como instrumento subjetivo de poder. Esta tendencia entiende el espacio como un objeto discursivo y cualquier significado que se le otorgue no es inherente al mismo sino proyectado mediante discursos políticos y geográficos (Murphy, 2004). Por tanto, el objetivo principal de la geopolítica crítica es develar los objetivos estratégicos que subyacen en los 
discursos de los agentes políticos a través de la deconstrucción de los mismos. De esta forma, el análisis desde la geopolítica crítica se nutre de las teorías de los filósofos posmodernos y sus técnicas deconstructivistas (Reuber, 2000).

En otras palabras, realiza un análisis crítico de los conceptos y la manera como se enfocan los discursos políticos, los mapas, los ensayos, las películas o casi cualquier medio para identificar lo que se conoce como el discurso subyacente, que surge de la fusión del poder y la autoridad en el contenido del lenguaje, resaltando en este la creación de suposiciones que generan narraciones incuestionables sobre algunas partes del mundo y las personas que las habitan, para justificar acciones militares y otras agendas de política exterior (Flint, 2006).

Otro de los puntos importantes de esta vertiente consiste en ilustrar que es imposible separar las esferas nacional e internacional, y que los actores no estatales, como las multinacionales, las organizaciones no gubernamentales y una variedad de grupos de protesta y movimientos por los derechos de los pueblos indígenas, las minorías, las mujeres, el llamado al comercio justo, la protección del medio ambiente, entre otros, también desempeñan un papel clave en la política global, al igual que los Estados (Flint, 2006).

Según la perspectiva crítica, la reproducción del conocimiento geopolítico tiene lugar en tres niveles. El primero se denomina el formal, que denota la construcción y reproducción del pensamiento geopolítico por intelectuales e instituciones académicas; el segundo es el llamado práctico, centrado en la reproducción de la geopolítica a través de la práctica cotidiana de los políticos a tra- vés de sus discursos de política exterior y los documentos oficiales; y por último el popular, que se refiere a la construcción de la identidad nacional y a las imágenes de otros pueblos y lugares en la cultura popular y los medios de comunicación (Omelicheva, 2016).

Los intereses estratégicos y geopolíticos rusos se plasman en las declaraciones de Putin, las cuales se caracterizan por hacer alusión explícita a la identidad nacional, al patriotismo, a los símbolos e historia de su nación, por generar orgullo en el pueblo y los líderes rusos, al igual que alentar el resentimiento antioccidental por subestimar la jerarquía internacional de Rusia al ignorar Estados Unidos y Europa sus planteamientos y posturas en los diversos escenarios multilaterales, y con el acercamiento de la OTAN a sus fronteras al integrar a su organización países de la desaparecida Unión Soviética.

A continuación, se revisarán y analizarán los planteamientos de Vladimir Putin en algunos de sus discursos desde el nivel práctico de la geopolítica critica, también conocido como discurso politico desde arriba, el cual se caracteriza por ejemplificar la construcción de narraciones y percepciones geográficas en tiempo real hechas por políticos profesionales (Omelicheva, 2016).

En 2006, en un discurso que marcó el comienzo del Año de la Lengua Rusa, Vladimir Putin instó a la intelectualidad rusa a promover el término Russkii mir (mundo ruso). Rápidamente este se popularizó en el discurso político y académico ruso. La frase se ha traducido a menudo como "civilización rusa" en las publicaciones occidentales, sin embargo, el término occidental de civilización es etimológicamente 
diferente al de la palabra eslava mir, que denota la comunidad cuando se utiliza junto con el término russkii. En la historia rusa, mir era una comunidad de autogobierno de propietarios campesinos conocidos por sus tradiciones conservadoras y reconocidos como guardianes de los valores nacionales ortodoxos. La palabra mir concentra la importancia relacionada con una idea antigua de que hay algo único acerca de Rusia y las raíces de los rusos en su identidad étnica, historia, cultura, pero que también provee o proporciona los nexos necesarios entre eras históricas que se busca encontrar en la frase mundo ruso (Omelicheva, 2016).

En este sentido, es importante entender que el concepto de Russkii mir integra no solo a los ciudadanos rusos, sino que ahora constituye un concepto abarcador que pretende aglutinar a los rusos residentes en países de las antiguas repúblicas soviéticas -y en otros países-, a los emigrantes y sus hijos, e incluso a las personas de habla rusa, en otras palabras, a todos los que sienten interés por Rusia (Herráez, 2015).

La ampliación de su significado genera que el término resulte un tanto impreciso, ya que abarca desde rusos étnicos a poblaciones de habla rusa, no solo en la propia Rusia o en el espacio postsoviético, sino a la diáspora rusa y los rusoparlantes repartidos en todo el mundo, es decir entre 20 a 40 millones de personas. Esta situación refleja la existencia de dos términos aplicables a la identidad rusa: mientras la palabra rusa russkie hace referencia a la identidad étnica rusa, rossiani lo hace a la ciudadanía rusa, situación que, en ocasiones, se emplea con una ambigüiedad estratégicamente calculada (Herráez, 2015).
Entonces, las bases de la identidad nacional rusa, promovida por el Kremlin bajo la rúbrica de mundo ruso, son su lengua y su cultura, por tanto, los límites geográficos de este geocuerpo imaginario denominado mundo no están limitados por las fronteras de la Federación Rusa, sino que abarcan todos los territorios poblados por los rusos étnicos y ortodoxos los cuales constituyen su núcleo (Omelicheva, 2016).

Los elementos descritos en los discursos de Putin no son nuevos. El 16 de agosto de 1999, los miembros de la Duma rusa se reunieron para aprobar su candidatura como primer ministro. Habló como un hombre que extrañaba las épocas cuando Moscú era toma$\mathrm{da}$ en serio. Afirmaba "Rusia ha sido una gran potencia durante siglos y aún lo sigue siendo. Siempre ha tenido y tendrá zonas de interés legítimo. No deberíamos bajar la guardia en este aspecto ni permitir que nuestra opinión sea ignorada”. Su política interna era restaurar la estabilidad, frenar lo que llamó las "revoluciones" que habían hundido a Rusia, y su política exterior era recuperar el lugar prominente de Rusia que le corresponde en los asuntos mundiales (Bullough, 2014).

En otro de sus discursos, el presidente ruso les dijo a sus embajadores en el 2014 con respecto al acercamiento de la OTAN a sus fronteras:

Los acontecimientos provocados en Ucrania son la expresión concentrada de la política de contención de comienzos de la Guerra Fría [ ... y] nuestros socios han estado convenciendo a Rusia durante las últimas dos décadas de sus buenas intenciones y de 
su voluntad de construir una cooperación estratégica conjunta. Sin embargo, de forma paralela, una vez tras otra han ampliado la OTAN y han desplazado el espacio político-militar que controlan cada vez más y más cerca de nuestras fronteras (Ballesteros Martín, 2014, p. 16).

Frente a la identidad nacional rusa y el irredentismo afirma:

...en Ucrania se ven amenazados nuestros compatriotas, la gente rusa y de otras nacionalidades, su idioma, su historia, su cultura y sus derechos legítimos garantizados precisamente por los convenios de la unión europea. al hablar de rusos y ciudadanos rusos me estoy refiriendo a las personas que se sienten parte de lo que llamamos de forma más amplia el mundo ruso, no necesariamente las personas cuyo origen étnico es ruso, sino todos los que se consideran rusos [...] nuestro país - precisó Putin-seguirá defendiendo enérgicamente los derechos de los rusos, de nuestros compatriotas en el extranjero, y que recurrirá para ello a todo el arsenal de medios que posee: desde los políticos y económicos hasta el derecho a la autodefensa previsto en el derecho internacional de las operaciones humanitarias (Ballesteros Martín, 2014, p. 28).

Putin está logrando con sus alocuciones el renacimiento en los rusos de los auténticos valores y principios espirituales de la nación, el sentimiento patriótico y una percepción redignificada de la memoria histórica y las tradiciones (cristianismo ortodoxo), para legitimar la aspiración rusa de dominar la región euroasiática (espacio vital) y rescatar la percepción sobre el verdadero papel que le corresponde a Rusia desempeñar en el sistema internacional (Pérez, 2015).
Al revisar los documentos desde el nivel práctico de la geopolítica crítica se observa que la protección de las minorías rusas en el exterior no es nueva por parte de Rusia, convirtiéndose en una de sus prioridades después de la implosión de la Unión Soviética. Lo anterior se refleja en diversas normas y leyes, al igual que varias acciones de política exterior. La Constitución Rusa, en su artículo 80, plantea la obligación de proteger a los rusos siendo el presidente el garante de sus libertades y derechos humanos. Por su parte, la Ley de 1999 sobre compatriotas en el exterior establece su protección oficial en el exterior, dejando abierta a interpretaciones las acciones oficiales por tomar, si es necesario implementarla. En el año 2008, en plena crisis con Georgia, Rusia elaboró un documento estratégico sobre política exterior que dice: "Rusia proveerá de protección comprensiva a los derechos y los intereses legítimos de los ciudadanos rusos y compatriotas residentes en el exterior" (Ferrero, 2016).

Por su parte, los conceptos rusos de política exterior de 1993 y de seguridad nacional de 1997 establecen como prioridad proteger los derechos de los rusos fuera de sus fronteras y respaldan el fortalecimiento de un espacio estratégico militar unificado, manteniendo presencia militar en regiones de interés estratégico con el objeto de promover el equilibrio militar-estratégico y tener capacidad de reacción en casos de crisis. En el año 2000 se actualizan ambos conceptos, y se reafirma así la defensa de los derechos e intereses de los ciudadanos rusos en otros países. Se vuelven a actualizar, bajo los mismos lineamientos, el concepto de política exterior en 2008 y el de seguridad en 2009 y 2013 ratificando como 
objetivo la protección global de los intereses y derechos de los ciudadanos rusos en el extranjero. Bajo estos parámetros Putin solicitó en el 2014 autorización para utilizar la fuerza a fin de defender a los rusos en Ucrania en caso de ser necesario (Ruiz, 2016).

Desde el estudio del discurso de Vladimir Putin y de los documentos oficiales se puede constatar que la defensa de los derechos de los ciudadanos rusos fuera de la Federación ha estado presente desde los años noventa, y que la postura de Putin frente a este tema ha sido coherente en el tiempo. Lo que ha variado son los tipos de acción que se han desarrollado para garantizar la defensa de los 25 millones de rusos que viven fuera de su patria.

\section{INTERVENCIÓN RUSA EN GEORGIA Y UCRANIA}

Con la desintegración de la Unión Soviética en 1991, Moscú perdió aproximadamente dos millones de kilómetros cuadrados de territorio, equivalente a la Unión Europea o la India. Rusia perdió la parte de Alemania que había conquistado en la Segunda Guerra Mundial y otros países exsoviéticos, que están ahora dentro de la OTAN. Otras antiguas posesiones soviéticas, como Georgia y Ucrania, cooperan estrechamente con Occidente en materia de seguridad. A pesar de la anexión de Crimea, de la guerra en Ucrania y la ocupación de Abjasia y Osetia del Sur, ha tenido que retirarse de la mayor parte de la llamada Nueva Rusia (Kotkin, 2016).

Junto a la pérdida territorial, también se generó una implosión que dejó fuera de Rusia a más de 25 millones de rusos. Este fenómeno generó uno de los principales factores de desestabilización de la frontera entre la Unión Europea y Rusia al ser utilizada estratégicamente por el Gobierno de Vladimir Putin la población rusa que se encuentra fuera de sus fronteras aplicando la siguiente estrategia: primero concede la ciudadanía rusa, pensiones y pasaportes a minorías residentes en estos Estados ("pasaportización”), segundo, esgrime la defensa de sus ciudadanos en otro territorio como excusa para intervenir en este, y, por último, busca controlar sus gobiernos y poblaciones (Ferrero, 2016).

Se denomina "pasaportización" la acción de integrar como ciudadanos de Rusia a individuos de origen ruso (russkie), rusoparlantes y personas que fueron ciudadanos de la extinta Unión Soviética (rossiani). Es una medida de poder blando para alcanzar sus fines políticos. Esta acción hace parte de la política descrita de protección de compatriotas fuera de las fronteras de Rusia (Herráez, 2015).

Con la estrategia descrita Rusia busca proteger o reintegrar a las poblaciones de origen ruso, por ejemplo en Estonia y Lituania donde ha repartido pasaportes a miles de rusófonos, en Moldavia donde la región independiente de Transnitria en el año 2014 presentó una solicitud de anexión a Rusia, y los casos de Abjasia y Osetia del Sur en Georgia, y Crimea, Lugansk y Donetsk en Ucrania, que a continuación se desarrollarán, donde se presentaron algunas de las denominadas revoluciones de los colores. El fin último de esta maniobra es la reconstrucción de la Nueva Rusia, término que rescató Putin de la época zarista (Ferrero, 2016), para restablecer la tradicional esfera de influencia rusa, a partir del discurso irredentista nacionalista. 
Para Rusia, las revoluciones de colores (Revolución de las Rosas en Georgia, 2003; Naranja en Ucrania, 2004; de los Tulipanes en Kirguistán, 2005) fueron alentadas por Occidente, provocando el establecimiento de gobiernos que apoyaban a Estados Unidos en sus objetivos estratégicos globales, a cambio del respaldo a políticas revisionistas y de enfrentamiento con Rusia, entre las que se destacan el interés de Ucrania y Georgia de ingresar a la OTAN y a la Unión Europea (González, 2010).

Como se mencionó, la Estrategia de Seguridad Nacional de la Federación Rusa considera estas revoluciones como una amenaza y señala desde su postura que la práctica de derrocar regímenes políticos legítimos, provocando inestabilidad interna y el conflicto, es cada vez más generalizada y culpa a Occidente de crear tensiones en la región Euroasiática. Para Moscú, el apoyo de Estados Unidos y la Unión Europea a las crisis de Ucrania, Georgia y otros Estados postsoviéticos han conducido a una profunda división en estas sociedades y la aparición de conflictos armados en estos países (Iglesias, 2016).

\section{GEORGIA}

Osetia del Sur y Abjasia, situados en el norte, del país son dos repúblicas vecinas de Rusia consideradas por Georgia como constituyentes, pero independientes de facto a lo largo de la historia. En agosto de 2008 se desencadenó un conflicto entre Georgia y estas dos repúblicas independentistas por razones históricas, étnicas y políticas. Este conflicto se dio como resultado de una serie de maniobras a nivel internacional entre diversos actores interesados en obtener mayor influencia sobre la estratégica zona del Cáucaso, para afirmar sus respectivos intereses geopolíticos (Pevarello, 2016).

\section{Revolución de las Rosas (2003)}

En el año 2003 se produce en Georgia la llamada Revolución de las Rosas, un golpe que llevó al poder a Mijeíl Saakashvili, quien cambió la política georgiana con un discurso prooccidental y nacionalista. Bajo su presidencia se da un acercamiento de Georgia a la OTAN lo cual profundiza las tensiones con Rusia dado el valor geoestratégico de Georgia en el Cáucaso, en particular el control de los oleoductos y gasoductos que desde Azerbaiyán llegan hasta Turquía y que interesan a Occidente para reducir el monopolio energético ruso (figura 3) (Pevarello, 2016).

Se destaca el oleoducto que une a Bakú, Tiflis y Ceyhan (BTC), el segundo más largo del mundo, capaz de suministrar a Occidente un millón de barriles de petróleo desde el Caspio hacia el Mediterráneo sin pasar por territorio ruso, y el gaseoducto Bakú, Tiflis y Erzurum, que llevará directamente gas natural a Europa atravesando Turquía y evitando el control energético de Rusia. En la unión energética del mar Caspio y el Negro, la posición geoestratégica de Abjasia es extremadamente relevante para Rusia, Georgia y Occidente debido a su cercanía con esta autopista energética que le da a la Unión Europea acceso al petróleo y gas de Asia Central (Ramírez, 2014). No hay que olvidar que desde la geopolítica neoclásica es fundamental controlar Asia Central por su posición geoestratégica y sus recursos de energéticos.

OASIS, N²6.Julio-Diciembre 2017.pp. 81-105 
Figura 3

Rutas de tránsito de gas y petróleo de Azerbaiyán y el Mar Caspio a través de Georgia

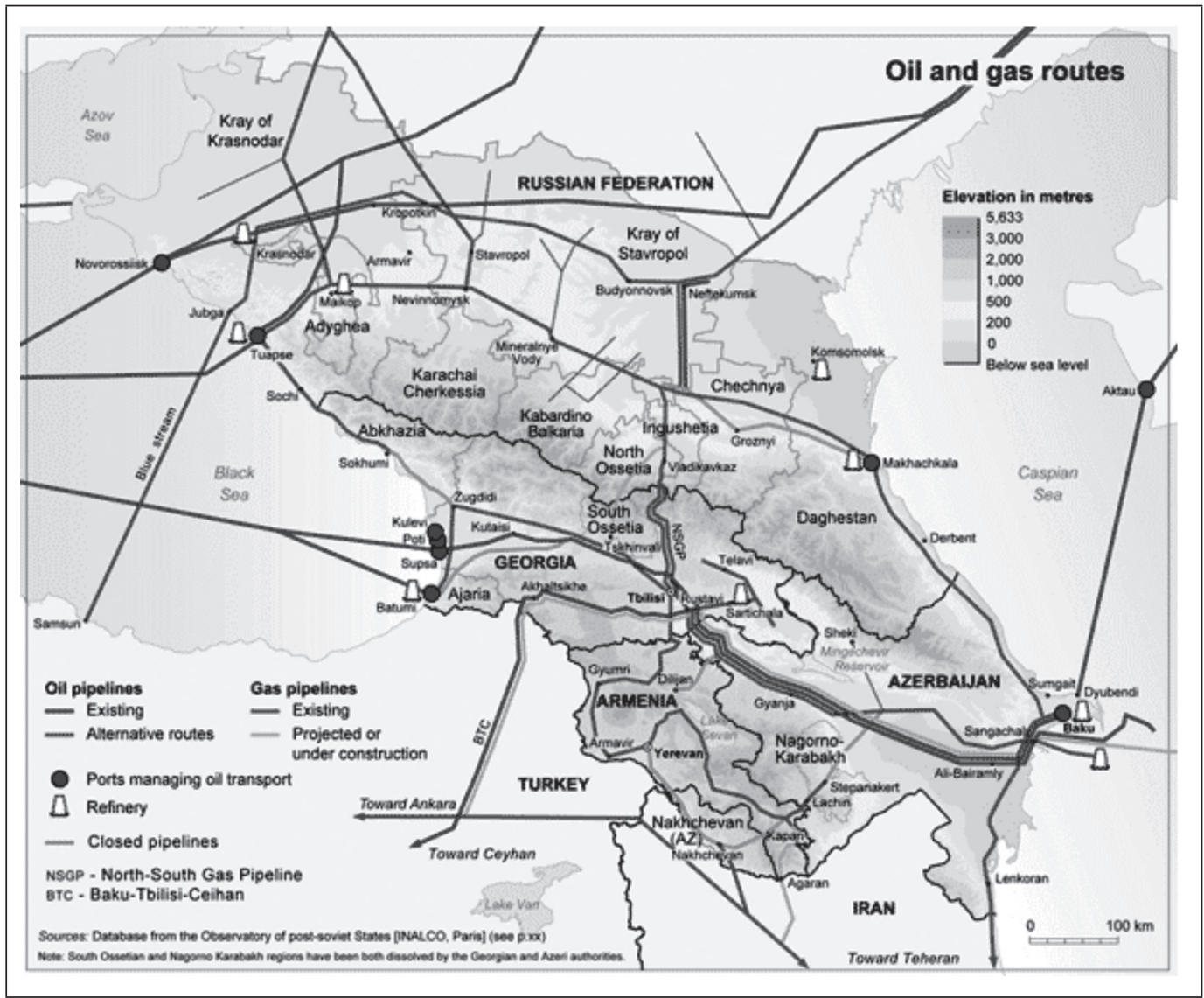

Fuente: Radvanyi y Rekacewicz (2008).

Osetia del Sur y Abjasia seguían con su política independentista, defendidas por fuerzas de paz rusas. Desde la elección de Saakashvili se mantuvo una tensión profunda en la zona, pero sin intervenciones militares e incluso proyectando planes de reconciliación. En 2006 se efectuó en Osetia del Sur un referéndum para anexarse a la Federación Rusa, el cual no reconoció Georgia, que triunfó con el 99\% de los votos de los separatistas (Pevarello, 2016).

En 2008, debido a la escasa presencia de población rusa en el Cáucaso sur, Rusia desa- 
rrollo la política de "pasaportización” con abjasios y osetios del sur, amparado por la Duma que desde 1991 por ley permite a cualquiera que hubiera sido ciudadano soviético solicitar un pasaporte ruso (Herráez, 2015). Lo anterior es ejemplo de la utilización de poder blando por parte de los rusos sobre la población caracterizada como rossiani.

\section{Conflicto armado en Osetia del Sur y Abjasia. La guerra de los cinco días (2008)}

En abril de 2008 se produjo una cumbre en la OTAN que trató el tema de incorporar a Georgia y Ucrania a la organización. Dentro de las diversas condiciones para el ingreso estaba la integridad territorial, algo que Georgia no podía asegurar, lo que llevó a un aumento de la tensión en la región. En agosto del mismo año se produjo un ataque georgiano a Osetia con el argumento de que se estaban cometiendo actos de limpieza étnica en contra de la población georgiana. Las tropas georgianas se movieron hacia Tsjinvali, capital de la república separatista, derrotando a las escasas fuerzas rusas que rodeaban la ciudad, mientras la mayoría de la población escapaba hacia Rusia. Moscú reaccionó esa misma noche, ingresando sus tropas a Osetia del Sur, mientras la aviación bombardeaba importantes bases militares en toda Georgia. La intervención rusa fue declarada como una misión de paz y fue decidida por el Comando Supremo ruso (Pevarello, 2016).

La firme reacción rusa al ataque de Georgia contra la zona separatista de Osetia del Sur la noche del 7 de agosto de 2008, puso en evidencia la categórica reafirmación de Rusia como potencia, y el hecho de que los rusos bajo el liderazgo de Vladimir Putin usarían todos los medios posibles, incluidos los militares, para defender sus intereses nacionales (González, 2010). Lo ocurrido en Osetia del Sur fue de gran relevancia, ya que era la primera vez que tropas rusas cruzaban una frontera reconocida internacionalmente para combatir en otro país, desde que lo hicieron en 1979 bajo la bandera de la Unión Soviética en Afganistán (Fernández, 2008).

Luego el conflicto se trasladó en Abjasia, que desplegó sus fuerzas a la frontera georgiana, por tal motivo Georgia acusó a Rusia de haber planificado la maniobra de Abjasia, pero rusos y abjasios lo negaron e incluso $\mathrm{Ru}-$ sia advirtió a las autoridades de abjasias de no invadir Georgia, puesto que se encontraban en misión de paz. El 12 de agosto finalizó el conflicto (Pevarello, 2016).

Rusia, Estados Unidos y países de la Unión Europea convocaron una reunión del Consejo de Seguridad, donde se produjo un enfrentamiento diplomático entre rusos y estadounidenses. Moscú los acusaba de haber planeado el ataque georgiano y de haber entrenado a sus militares. Washington, por el contrario, afirmaba que habían invadido a Georgia y no actuaban como una fuerza de paz. Cualquier posibilidad de intervención de la ONU fue bloqueada por el veto ruso y se produjo un escenario diplomático que recordaba la Guerra Fría, por las posiciones de rusos y estadounidenses. En esta situación, la Unión Europea asumió el papel de mediador y logró la firma de un acuerdo entre las partes (Pevarello, 2016). 
La respuesta de los rusos en este conflicto se caracterizó por la rapidez y eficacia al mantener el statu quo en la zona del Cáucaso y debilitar los intereses políticos de Georgia. Asimismo, logró frenar los movimientos de la OTAN al bombardear bases militares de esta organización y debilitar las condiciones de seguridad de gaseoductos y oleoductos estadounidenses, impidiendo la penetración occidental en sus áreas de especial interés. Por otra parte, Vladimir Putin recuperó la retórica imperial rusa, reafirmando su intención de ser una superpotencia al mismo nivel de Estados Unidos y algunos países de Europa (Pevarello, 2016). Finalmente, Moscú reconoció a Osetia del Sur y Abjasia como Estados independientes, postura que contó con escaso apoyo internacional. Desde entonces a este conflicto, junto a otros similares en los antiguos países del bloque soviético, se les conoce como conflictos congelados.

\section{UCRANIA}

Sumados a los factores geopolíticos rusos ya analizados, dos son los aspectos más relevantes relacionados con Ucrania que son de gran interés estratégico para Rusia desde la geopolítica neoclásica: el acceso al Mar Negro, y los gasoductos y oleoductos rusos que proveen a gran parte de Europa.

Desde los tiempos de Catalina la Grande, a finales del siglo XviII, Rusia siempre ha procurado el control del Mar Negro, buscando salida a los mares calientes del sur para garantizar la movilidad de su flota durante todo el año. Lo anterior otorga un gran valor estratégico a la península de Crimea, donde se encuentra la base naval de Sebastopol que hace parte de la flota del mar Negro la cual, junto a las flotas del Báltico, del Norte y del Pacífico, componen el poder naval ruso (figura 4). La flota del mar Negro es la responsable de ejercer el control ruso sobre el Mediterráneo (Ballesteros, 2014).

Por otra parte, Rusia proporciona entre el 30 al 40\% del gas, así como el 18\% del petróleo que consume la Unión Europea. Estas cifras han tenido una tendencia creciente en los últimos años, aumentando la dependencia energética europea. El interés ruso en Ucrania consiste en que varios de sus gasoductos y oleoductos atraviesan este país (aproximadamente el $50 \%$ del gas ruso pasa por Ucrania), lo que incrementa el valor geopolítico de este territorio para los rusos (figura 5) (Ballesteros, 2014). Como se mencionó, los recursos naturales fortalecen los poderes duros y blandos rusos para lograr cumplir con sus objetivos estratégicos. 


\section{Figura 4}

Ubicación de la base naval de Sebastopol en la península de Crimea

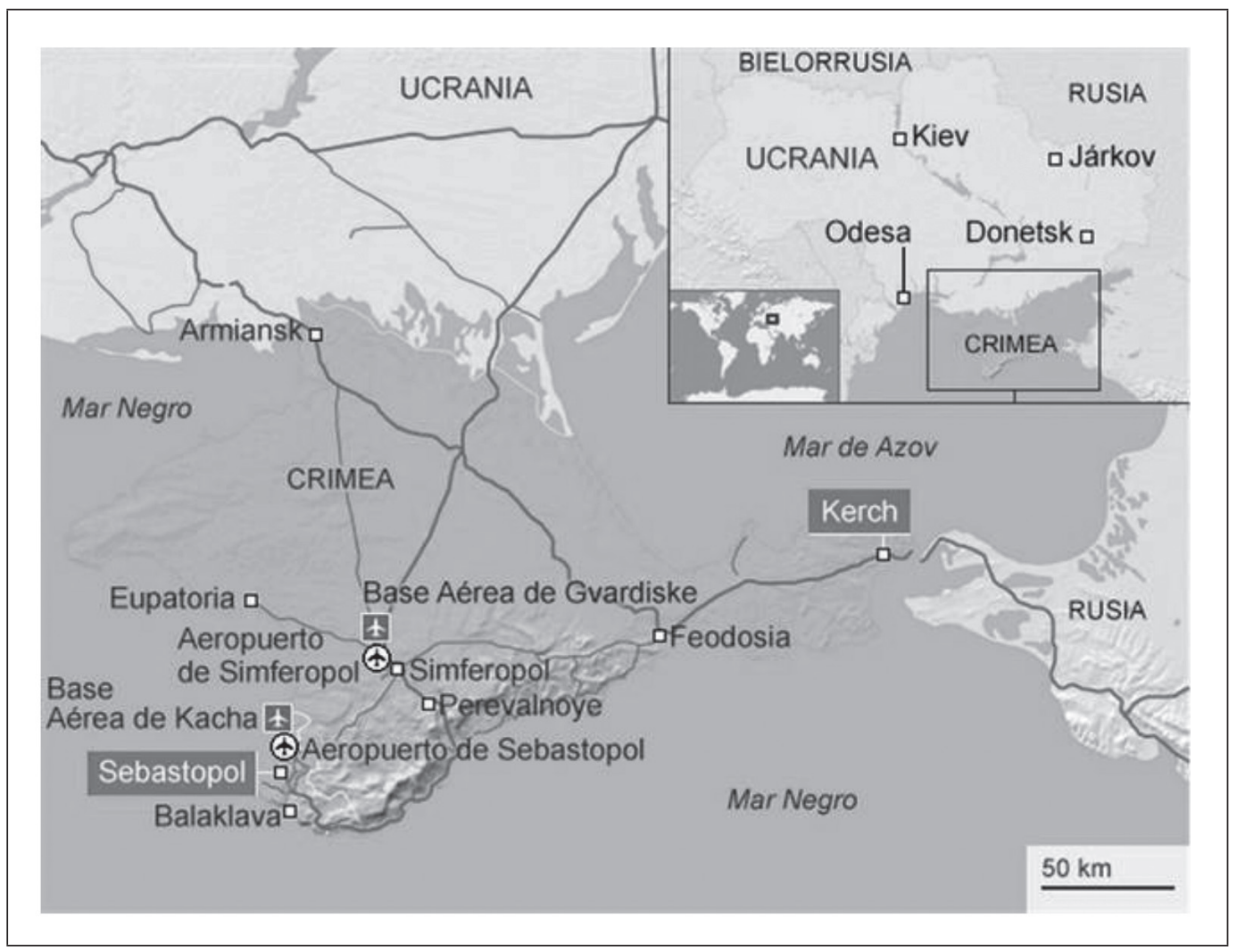

Fuente: Defensa nacional y el mundo (2014). 
Figura 5

Rutas de tránsito de gas y petróleo ruso a través de Ucrania

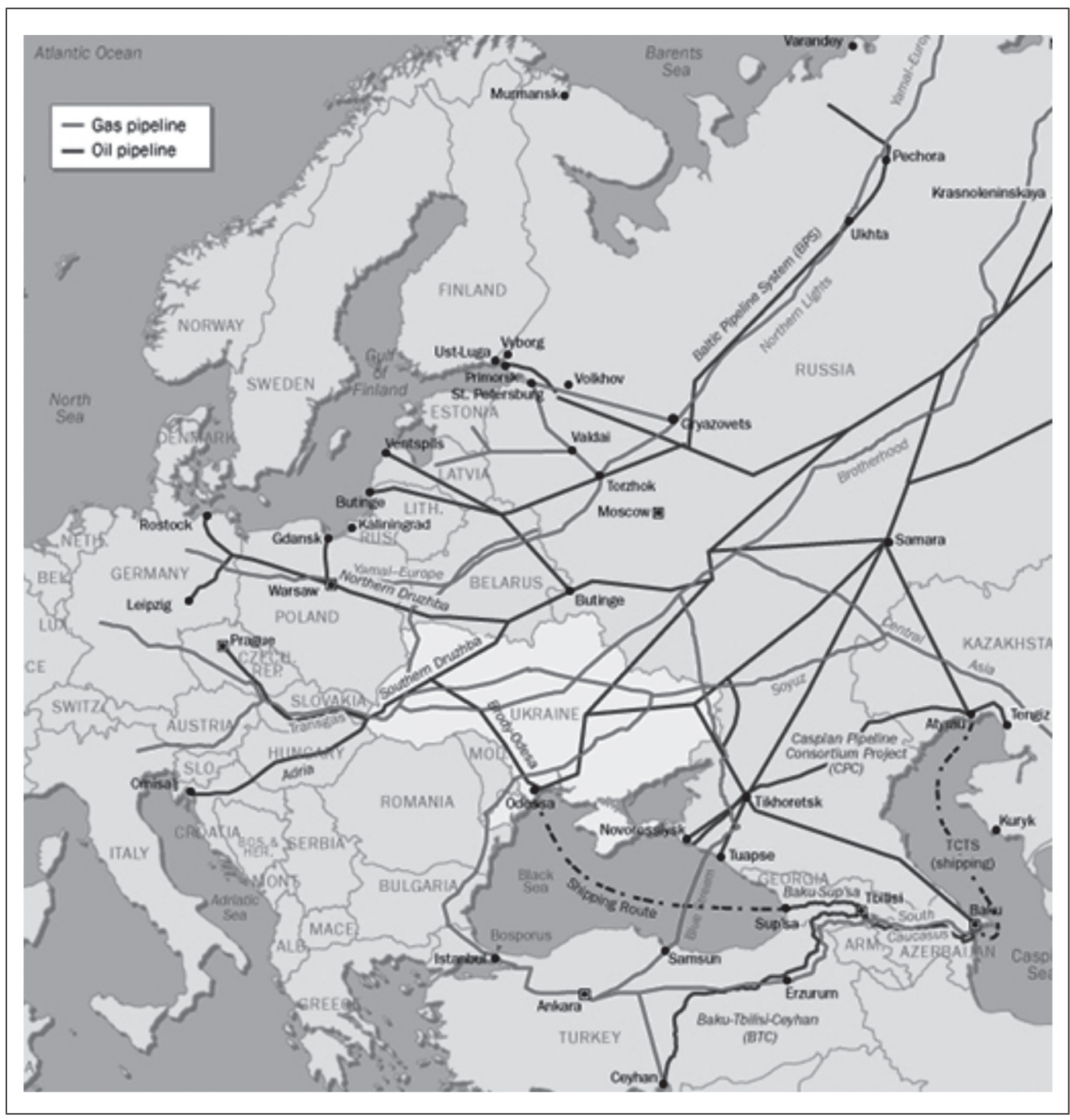

Fuente: S\&P Global (2014). 
Con respecto al fenómeno irredentista en Ucrania, son de gran relevancia dos hechos que potenciaron la reaparición del nacionalismo eslavo en este país: la Revolución Naranja (2004) y El Euromaidan (2013) que implicaron un cambio del tradicional acercamiento de Ucrania a Rusia por uno hacia Occidente.

\section{La Revolución Naranja (2004)}

Se produce en el contexto de las elecciones presidenciales ucranianas entre el 2004 y el 2005, entre el candidato prorruso Viktor Yanukóvich y el prooccidental Viktor Yúshchenko. En la primera vuelta venció Yúshchenko y en la segunda ronda se declaró el triunfo de Yanukóvich. Diversas misiones de observación electoral dieron informes negativos, lo cual motivó a una masa de color naranja que reunió aproximadamente 600.000 personas en su punto máximo para protestar durante dos semanas en las calles de Kiev por los fraudulentos resultados (Ruiz, 2016).

Ante esta situación, una parte de la Duma desconoció los resultados y nombró a Yúshchenko como nuevo presidente de Ucrania, con el respaldo de las regiones del oeste y centro prooccidentales. Sin embargo, las regiones prorrusas sur orientales declararon al recién nombrado presidente ilegítimo e incluso amenazaron con una secesión, lo cual generó tensión entre los bandos. Finalmente, el Tribunal Supremo ucraniano declaro inválida la segunda vuelta y convocó nuevas elecciones, que contaron con 12.000 observadores internacionales, en las que definitivamente triunfo Yúshchenko. Para los prooccidentales, la Revolución Naranja fue una protesta contra la corrupción y a favor de la libertad y una democracia transparente. Para los prorrusos fue un instrumento del imperialismo estadounidense (Ruiz, 2016).

La importancia de la Revolución Naranja radica en las consecuencias que tuvo para la gestación del nacionalismo eslavo dentro de Ucrania, en tanto se vincula a las Revoluciones de Colores que se producen dentro del espacio postsoviético, en contraposición a supuestos regímenes autoritarios, y se muestran a favor de la democracia liberal, dándoles un carácter prooccidental, lo que crea una confrontación directa con el proyecto paneslavista irredentista que busca la unión de los pueblos eslavos en torno a una identidad común.

De esta manera, los sectores de la población que se identifican con los movimientos eslavistas y no con el sistema de creencias y valores occidentales terminaron siendo rechazados y marginados por el nuevo régimen, el cual desentendió las aspiraciones de las regiones de población rusófona. Lo anterior generó expresiones políticas cada vez más extremas en el oriente ucraniano (Donestk, Lugansk y Zaporizhie) donde más del $80 \%$ de la población es de origen ruso (RT, 2016).

\section{EL EUROMAIDAN Y EL CAMBIO DE GOBIERNO (2013)}

Este fenómeno surge con las numerosas y masivas protestas que estallaron en el mes de noviembre de 2013, cuando la administración de Viktor Yanukovich se negó a firmar el tratado de asociación con la Unión Europea, manteniendo una posición favorable hacia Rusia y hostil hacia Occidente. La negativa de 
asociarse con la UE hizo que los sectores a favor de una integración reaccionaron mediante el estallido de numerosas revueltas con el objetivo de presionar al Gobierno para firmar la asociación económica con la Unión Europea (Russia Beyond the Headlines, 2016).

En este punto, Estados Unidos y la Unión Europea brindaron apoyo financiero y mediático a los sectores opositores ucranianos que se sentían cercanos a Occidente, viendo la oportunidad de ampliar su zona de influencia, con lo cual alteraron el orden geopolítico en la región e hicieron de Ucrania un aliado del mundo occidental. Estos movimientos también pretendían privar a Rusia de la base marítima de Sebastopol, a fin de negar su acceso al Mediterráneo y limitar cualquier acción futura que pudiera realizar para consolidarse como un actor mundial, en otras palabras, "Occidente quiere la adhesión de Ucrania a la OTAN, con el fin de privar a Rusia de su acceso al Mediterráneo. Mientras que Rusia quiere sencillamente recuperar Crimea para alejar tal eventualidad. Crimea es, en efecto, el único acceso de Rusia a los mares cálidos" (Pougala, 2016).

Ahora bien, pese a la represión inicial por parte de las autoridades y la negativa del Gobierno de asumir compromiso alguno respecto a la Unión Europea, la tensión y el temor al estallido de una guerra civil llevaron al Gobierno a entablar una mesa de negociaciones con los prooccidentales que no obtuvo resultados concretos. Finalmente, el Parlamento de Ucrania terminó por destituir al presidente Viktor Yanukovich, modificó la constitución y convocó a elecciones anticipadas para el 25 de mayo de 2014 (RT, 2016).

La presidencia fue ganada por Petró Poroshenko, un magnate industrial del chocolate favorable a los intereses occidentales. Sin embargo, se produjo un evento que marcó la expansión de la idea nacionalista irredentista: la península de Crimea (única república autónoma de Ucrania) se escindió y se integró a Rusia por medio de un referendo celebrado el 14 de marzo de 2014, con un 96\% de los votos favorables a la independencia y a la reunificación con Rusia, consolidando los intereses geopolíticos rusos en el Mar Negro (Ruiz, 2016).

Ante la amenaza de una desintegración, la nueva administración prooccidental del país introdujo medidas como la prohibición del lenguaje ruso en las escuelas, el uso de símbolos nacionales rusos y la represión de cualquier protesta que reivindicara la federalización del país o que concentrara su atención hacia el referente eslavo por excelencia: Rusia. De este modo, se produce la segunda causa del desencadenamiento nacionalista sobre el oriente ucraniano, que se va a ver reflejado en el proyecto secesionista de Donbass, que administrativamente comprende las regiones de Lugansk y Donetsk, el cual se manifestó en los enfrentamientos armados con el ejército ucraniano por parte de sus fuerzas de autodefensa respaldadas por Rusia (figura 6). 
Figura 6

Ubicación de Donbass en Ucrania

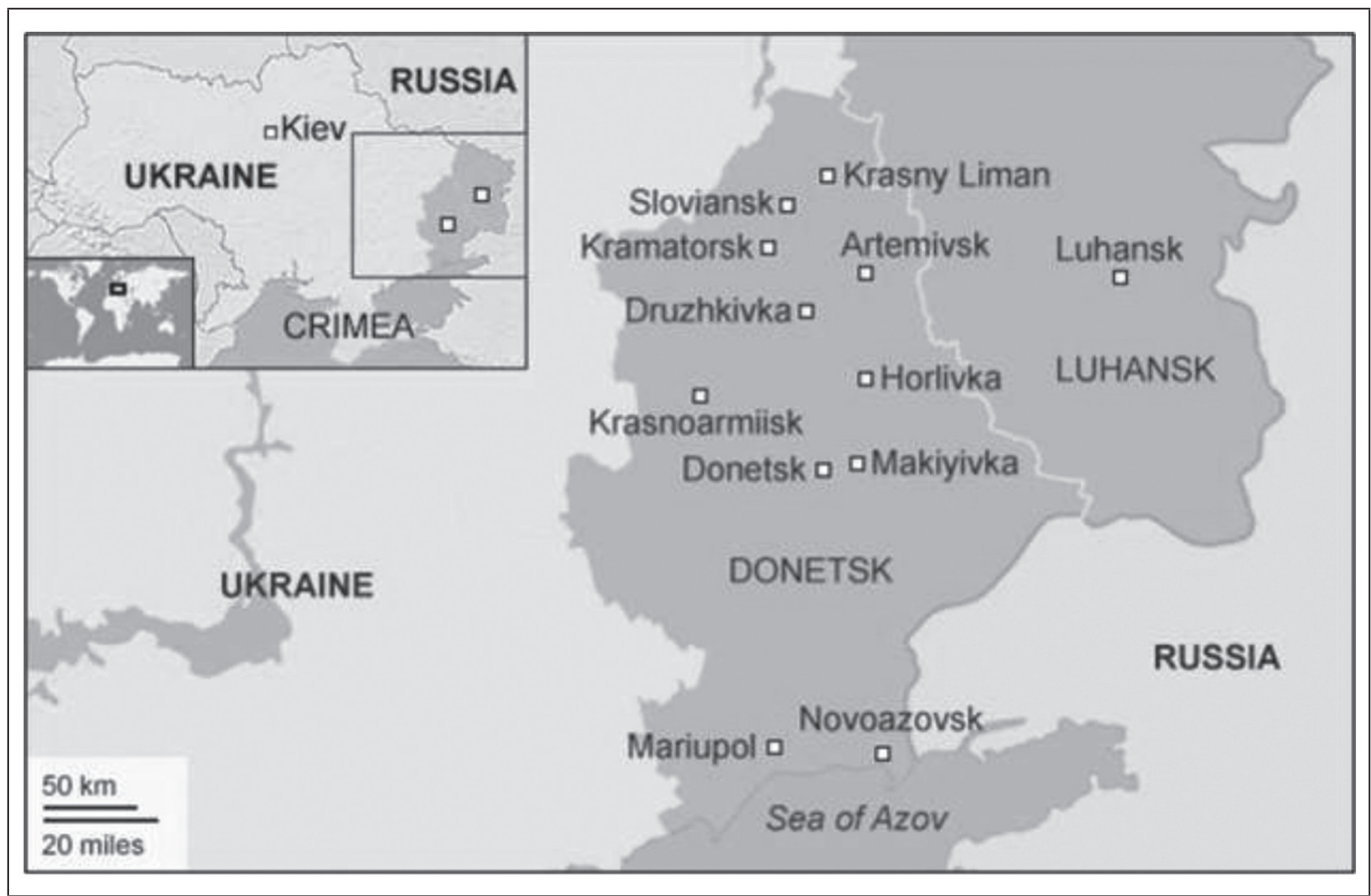

Fuente: BBC (2014b).

Pese a que los Acuerdos de Minsk (2014 y 2015) buscaban solucionar, o al menos aliviar el conflicto, la contienda continúa abierta y se está transformando en un nuevo conflicto congelado en el espacio postsoviético, donde Rusia mantiene una ambigüedad acerca de una intervención más directa sobre Donbass, con el fin de disuadir a Kiev de reconquistar el territorio perdido (Morales, 2016), en una nueva demostración (al igual que los casos de Osetia del Sur y Abjasia) de cómo los rusos están creando un cinturón de seguridad entre ellos y Europa, en territorios que pertenecían a países que conformaban el antiguo bloque soviético.

\section{CONCLUSIONES}

La expansión de los intereses estadounidenses en colaboración con la OTAN a países como Ucrania o Georgia, con la pretensión de ganar poder estratégico en la región, acercándose progresivamente hacia las fronteras rusas, ha generado una desestabilización en la zona que es percibida por la doctrina militar rusa como una gran amenaza para su seguridad e intereses 
geopolíticos. Para contrarrestar dicha amenaza Rusia utiliza fenómenos de irredentismo en antiguas repúblicas soviéticas que se acercan a Occidente, anexando regiones a su territorio o desestabilizando países que se alejan de su área de influencia, como estrategia para frenar el avance de sus adversarios.

El irredentismo como fenómeno derivado de la ideología nacionalista en su vertiente conservadora sigue siendo vigente en el contexto internacional, $\mathrm{y}$ ha generado el surgimiento de nuevos Estados como Osetia del Sur, conflictos armados como el de Lugansk y Donetsk, o anexiones territoriales como Crimea, todas asociadas a los intereses geopolíticos de Rusia.

La defensa de los ciudadanos rusos fuera de las fronteras de Rusia es un interés clave para Moscú y se encuentra en todos sus documentos doctrinales, tiene su origen normativo en la Constitución y se viene implementando desde inicios de los años noventa. No es una estrategia nueva creada por Vladimir Putin con su arribo al poder, sin embargo, él sí la ha aplicado de forma contundente dentro la estrategia rusa en países como Ucrania y Georgia.

Los ámbitos ideológicos, culturales, nacionales y sociales desde la geopolítica neoclásica son temas secundarios que son aprovechados para alcanzar los intereses estratégicos y políticos que se supeditan tanto al territorio como a la supervivencia y el poder de los Estados. Todo lo contrario sucede con la corriente crítica, donde estos ámbitos nutren y reproducen el conocimiento geopolítico en los discursos políticos y documentos oficiales.

\section{REFERENCIAS}

Arbatov, A. (2016). Russian Foreign and Security Policy. Moscow: Carnegie Moscow Center.

Ballesteros Martín, M. Á. (2014). Ucrania y el nuevo liderazgo geopolítio ruso. En Estrategicos, I. E. Panorama geopolitico de los conflictos 2014 (pp. 9-40). Madrid: Imprenta Ministerio de Defensa. ввС (2014a). Ukraine crisis: 'International monitors seized' in Sloviansk. Recuperado de http://www.bbc. com/news/world-europe-27162941

BвС (2014b). ¿Benefician a Rusia los «conflictos congelados» de la antigua URss? Recuperado de www. bbc.com/mundo/noticias/2014/09/140911_rusia_ucrania_conflictos_congelados_lav

ввС (2016). Los misiles con capacidades nucleares que Rusia está desplegando en Kaliningrado, el enclave que tiene en plena Unión Europea. Recuperado de http://www.bbc.com/mundo/noticias-internacional-37601433

Bullough, O. (2014). Vladimir Putin y la reconstrucción de la Rusia "soviética". $B B C$ Mundo. Recuperado de http://www.bbc.com/mundo/ noticias/2014/03/140328_putin_rusia_sovietica_wbm

Cardona, J. A. (2012). Escenario geopolitico del siglo XXI. Bogotá: Coordinación Editorial División de Investigación ESDEGUE.

Carvajal Aravena, P. (2007). Geopolítica de los entornos y sociedad del riesgo. Una interpretación desde la geopolítica crítica. el caso chileno. Revista Politica y Estrategia (108), 46-70.

Centro de Estudios Estratégicos de la ANEPE (2014). El irredentismo: ¿un problema de seguridad contemporáneo? Santiago de Chile: ANEPE. 
Defensa Nacional y el Mundo (2014). Drama y dolor en Ucrania al perder una base aérea en Crimea. Recuperado de http://defensanacional.argentinaforo.net/t7666p150-ucrania-al-borde-deuna-revolucion

Domínguez, R. (2013). Condicionantes en el diseño de la política exterior de Italia y Espańa a principios de siglo xx. La Balsa de Piedra, (4), 1-23.

Fernández, R. (2008). Guerra en el Caucaso. Guerra abierta entre Rusia y Georgia. El País. Recuperado de http://elpais.com/diario/2008/08/10/internacional/1218319201_850215.html

Ferrero Turrión, R. (2016). Los otros "conflictos" en la frontera ruso-europea. En Ramas, R. R. Ucrania: de la revolución del Maidán a la Guerra del Donbass (pp. 307-318). Salamanca: Comunicación Social. Ediciones y publicaciones.

Fettweis, C. (2000). Sir Halford Mackinder, geopolitics and policy making in the 21 St century. Parameters, 30 (2), 58-71.

Flint, C. (2006). Introduction to geopolitics (2 ed). London: Routledge.

Gómez, E. (2008). Historia de las ideologías políticas, Proyecto Agora. Medellín: Fondo Editorial Universidad EAFIT.

González, F. J. (2010). Las claves de la política exterior y de seguridad de la federación Rusa: oportunidades para España. Madrid: Fundación Ciudadanía y Valores.

Herráez, P. S. (2015). La pugna por el espacio postsoviético. La cuestión de las minorías rusas. En Estratégicos, I. E. Panorama geopolitico de los conflictos 2015 (pp. 57-92). Madrid: Imprenta Ministerio de Defensa.

Iglesias, M. L. (2016). La Estrategia de Seguridad Nacional de la Federación Rusa. Madrid: Instituto Español de Estudios Estratégicos.
Kagan, R. (2008). El retorno de la historia y el fin de los sueños. Madrid: Taurus.

Klare, M. (2003). The new geopolitics. Monthly Review, 55 (3), 51-56.

Kotkin, S. (2016). Russia’s perpetual geopolitics. Returns to the historical pattern. Foreign Affairs, 95 (3) 2-9.

Morales, J. (2016). Ucrania entre Occidente y Rusia: la dimensión internacional del conflicto. En Ruiz Ramas, R. Ucrania. De la Revolución del Maidán a la Guerra del Donbass (pp. 265-294). Salamanca: Comunicación Social. Ediciones y Publicaciones.

Murphy, A. (2004). Is there a politics to geopolitics? Progress in Human Geography, 28 (5), 619-640.

Ó Tuathail, G. (1996). The patterned mess of history and the writing of critical geopolitics: a reply to Dalby. Political Geography, 15 (6/7), 661-665.

Ó Tuathail, G. D. (2006). The geopolitics reader. London: Routledge.

Omelicheva, M. Y. (2016). Critical geopolitics on Russian foreign policy:Uncovering the imagery of Moscow's international relations. International Politics, 53 (6), 708-726.

Pérez, C. (2015). El poder de todas las rusias: la influencia de la identidad eslava y la identidad contrastiva sobre la politica exterior de la Federación Rusa. Madrid.

Pevarello, G. (2016). Pensamiento común desde la periferia. Recuperado de https://pensamientocomundesdelaperiferia.wordpress.com/2013/12/08/ implicaciones-internacionales-del-conflicto-rusogeorgiano-en-2008/

Polgati, A. C. (2007). Análisis crítico de la geopolítica contemporánea. Revista Política y Estrategia (108), 29-45.

Pougala, J. P. (2016). ¿Cómo ganar una guerra sin combatir según Sun Tzu? El ejemplo de Rusia en Crimea. Espiadigital. Recuperado de http:// 
www.elespiadigital.com/index.php/noticias/ geoestrategia/4854-icomo-ganar-una-guerrasin-combatir-segun-sun-tzu-el-ejemplo-de-rusiaen-crimea

Programa de las Naciones Unidas para el Desarrollo (2013). Informe Regional de Desarrollo Humano 2013-2014 - Seguridad ciudadana con rostro bumano: diagnóstico y propuestas para América Latina. Panama: Alfa Omega Impresores.

Radvanyi, J.y Rekacewicz, P. (2008). Projets concurrents de gazoducs et d'oléoducs au Caucase. Le Monde diplomatique. Recuperado de http://www.mondediplomatique.fr/cartes/projetsgazpetrole

Ramírez, M. D. (2014). Georgia y sus territorios secesionistas: más allá del punto de no retorno. En Estratégicos, I. E. Panorama geopolitico de los conflictos 2013 (pp. 101-126). Madrid: Imprenta Ministerio de Defensa.

Reuber, P. (2000). Conflict studies and critical geopolitics - Theoretical concepts and recent research in political geography. Geojournal, 37-43.

RT (2016). Guerra civil en Ucrania. Recuperado de https://actualidad.rt.com/themes/view/112919ucrania-revolucion-protestas-ue

Ruiz Gonzalez, F. J. (2016). Crimea. En Ruiz Ramas, R. Ucrania. De la Revolución del Maidán a la Guerra del Donbas (pp. 319-328). Salamanca: Comunicación Social. Ediciones y Publicaciones.
Ruiz González, F. J. (2016). Geopolítica y política de seguridad. En Ramas, R. R. Ucrania. De la Revolución del Maidán a la Guerra del Donbass (pp. 295-305). Salamanca: Comunicación Social Ediciones y Publicaciones.

Ruiz Ramas, R. (2016). El teatro multipolar: hacia un nuevo desorden global. En Ruiz Ramas, R. Ucrania: de la Revolución del Maidan a la Guerra del Donbass (pp. 329-359). Salamanca: Comunicación Social Ediciones y Publicaciones.

Ruiz Ramas, R. (2016). Oligarquía, regionalismo e inestabilidad: el sistema político ucraniano. En Ucrania. De la Revolución del Maidan a la Guerra del Donbass (pp. 189-213). Salamanca: Comunicación Social. Ediciones y Publicaciones.

Russia Beyond the Headlines (2016, 04 27). Russia Beyond the Headlines. Recuperado de https:// es.rbth.com/

Sinovets, P. y Renz, B. (2015). Russia’s 2014 Military Doctrine and beyond: threat perceptions, capabilities and ambitions. Research Division - NATO Defense College Roma - Research Paper n. 117. S\&P Global (2014). Oil, gas pipelines transiting Ukraine. Recuperado de http://www.platts.com/newsfeature/2014/naturalgas/ukraine-crisis-energyimplications/map-oil-gas-pipelines 